In the Special Issue on Multicultural Social Justice Leadership Development Guest Editor: Carlos P. Zalaquett, University of South Florida

\title{
Three Issues, Three Approaches, Three Calls to Action: Multicultural Social Justice in the Schools
}

\author{
Aretha F. Marbley \\ Texas Tech University \\ Krista M. Malott \\ Villanova University \\ Ann Flaherty \\ University of Pittsburgh \\ Helyne Frederick \\ Texas Tech University
}

\begin{abstract}
This article provides case studies, statistics, and social justice advocacy as lenses to discuss three areas related to multicultural social justice in school settings. Each case study is followed by a reflection on the authors' experiences. The article culminates with suggestions, guidelines, and recommendations for applying social justice advocacy to a school setting.
\end{abstract}

Keywords. social justice; schools; school counseling; racism; multiracial; discipline policies; service learning; leadership development 
We live in a world in which we need to share responsibility. It's easy to say, "It's not my child, not my community, not my world, not my problem." Then there are those who see the need and respond. I consider those people my heroes. Fred Rogers (Hudson, 2007, p.1).

\section{Multicultural Social Justice in the Schools}

The American Counseling Association (ACA) is among the frontrunners in the multiculturalism movement. In March of 2010 in Pittsburgh, Pennsylvania, ACA took another giant step by endorsing the first Multicultural Social Justice Leadership Development Academy (MSJLDA). With the launching of the Leadership Academy, multiculturalism, the fourth force in counseling, made a public commitment to multicultural social justice advocacy for clients and students.

According to Ratts, DeKruyf, and Chen-Hayes (2007), social justice advocacy is a key task for $21^{\text {st }}$ century school counselors. As long as Black children continue to sit together in the cafeteria (Tatum, 2003), as long as one child is "left behind," and as long as the academic gap of marginalized children continues, the need for social justice leadership also expands, specifically, the need for social justice advocacy in school settings. To illustrate the importance of leadership and advocacy, the authors use theory, narratives, and data to describe three instances whereby social justice advocacy was used to address racially unjust discipline policies, discriminatory treatment of multiheritage students, and service learning programming.

\section{Frameworks for Social Justice Advocacy in School Settings}

We chose to apply ACA's advocacy competencies and social justice advocacy. We believe social justice advocacy is an essential and necessary tool for working with children who are marginalized. Consistent with having the tool is having the competencies to do the work. Thus, our social justice advocacy work in school settings is grounded in the competencies put forth by Lewis, Arnold, House, and Toporek's (2003), and also consistent with Hipolito-Delgado and Lee's (2007) stance that those who are involved in social justice in school settings allow the practices of social justice advocacy in their work as counselors, school counselors, and counselor educators to reduce various forms of oppression.

\section{Social Justice Advocacy}

Social justice advocacy, a universal, though sometimes controversial approach, is the first framework to set the stage for our multicultural social-justice work in school settings. Steele (2008) states that social justice advocacy incorporates scholarship and variations on traditional forms of counseling for the purpose of challenging laws, policies, or practices that are adverse to the mental health of individuals who are marginalized on the basis of their social status. We believe that this must include children and their personal narratives. 
In essence, social justice advocacy in school settings means that school counselors are to serve as advocates for students in the areas of leadership, collaboration, and systemic change. In fact, this position is strongly delineated in the American School Counselor Association's (ASCA) national model for school counselors which states "Advocating for the academic success of every student is a key role of school counselors and places them as leaders in promoting school reform" (ASCA, 2003, p. 24).

According to ASCA's National Model, school counselors' advocacy efforts are aimed at eliminating barriers and creating opportunities and access for student development, student learning, and a quality education (ASCA, 2003). In short, this applies the "village" concept of calling for collaboration with all major school stakeholders in order to help students meet their needs. Ultimately, social justice advocacy means real systemic change to foster student success in schools.

\section{The Counseling Advocacy Competencies}

The second framework that grounds our work in school settings is the ACA advocacy competencies. Lewis et al.'s (2003) advocacy competencies model is centered on three levels of advocacy: client/student, school/community, and public arena. Each level of advocacy contains two domains and specific competency areas that emphasize advocacy with and on behalf of an individual. For school professionals, the client/student level of advocacy focuses on the domains of student empowerment and student advocacy. Here, school counselors may use direct counseling to empower individuals, which provides advocacy at the individual level.

The school/community level focuses on the domains of community collaboration and systems advocacy. At this level, the school counselor and other professionals use environmental interventions (e.g., access needed resources and services and identify support systems) to advocate for students. Last, the public arena domain focuses on public information and social and political advocacy. It is concerned with informing the public about systemic barriers that affect student development and how helping professionals can shape school policy. To be effective, this model requires school professionals to engage in all three levels of advocacy.

Accordingly, from a social justice perspective, advocacy moves beyond counseling or teaching to suggest the importance of changing systems that include familial, educational, legal, penal, political, health and mental health services. The goal is to increase access to services for school children who have been marginalized, that is, excluded, ignored, or relegated to the outer edge of academic success. Described in our narratives below are the students who did not have access to the resources they needed in order to be successful. The following are examples of our counseling work and professional experience in school settings, which include actual cases. Closing commentary include audience responses from the 2010 MSJLDA and recommendations for applying social justice strategies in schools.

\section{Case \#1: Reforming DAEPs for Equity for All Children - Marbley}

A publication by the Texas Education Agency (2007) provides an overview of the history of the disciplinary alternative education policy (DAEP) instituted in Texas in 1995. Students are placed in disciplinary alternative schools for the purpose of providing temporary student placements for behavior management. Typically, this is an alternative for suspension or expulsion and 
assignments to such facilities can be discretionary or mandatory. Students can be removed from their originating school and be sent to an alternative school if they: (a) engage in conduct punishable as a felony, (b) commit a series of specified serious offenses while on school property or attending a school sponsored activity, or (c) commit other violations specified in student codes of conduct developed by individual school districts (Cortez \& Robledo-Montecel, 1999).

The expectation was that students who have committed offenses warranting disciplinary actions would receive the appropriate personal attention and, at the same time, they would be learning and gaining additional support from qualified and dedicated adults. It was expected that such disciplinary programs could better engage students in the learning process and that increased school engagement would reduce problematic behaviors. However, Cortez and RobledoMontecel (1999) noted that, for the most part, "Alternative educational programs are being used as dumping grounds for 'undesirable' students who, once there, get little or no support" (p. 3).

Statistics demonstrate that a disproportionate number of male students of color receive serious disciplinary actions in schools across the nation (Barbarin, 2010). Barbarin (2010) has described the problem and its implications on a national scale, noting that "Teachers may misinterpret boys' behaviors, become frustrated, distance themselves emotionally, and resort to overly punitive responses to deal with the problems. This approach exacerbates rather than decreases the problems of African American boys" (p. 83).

This phenomenon has come to be recognized by scholars as the "school to prison pipeline," whereby empirical evidence has shown that youth of color who are expelled or suspended are more likely to drop out, commit a crime, or end up incarcerated as an adult (Advancement Project and The Civil Rights Project at Harvard University, 2000). The same study found that schools with predominantly students of color are more likely to adopt zero-tolerance discipline tactics, and these tactics promote greater rates of expulsion or suspension as a solution to any behaviors deemed "problematic."

In Texas the 2005-2006 academic year showed a disturbing trend in disciplinary actions that mirrored national statistics. Forty-eight percent of DAEP placements consisted of Hispanic students, $25.8 \%$ were African American students, and $25.2 \%$ were White students. Approximately $79 \%$ of those placements were male students. The most common reasons for placement were cited as violation of school codes of conduct $(64.7 \%)$ and use of controlled substances (12.5\%) (Texas Education Agency, 2007). The following case demonstrates one professional's attempt to address this systemic problem.

\section{Narrative}

Dr. Crystal Lemont, an African American faculty member at a Texas university, discovered that school administrators who are primarily White in a Texas school district disproportionately assigned low socioeconomic status African American and Hispanic students to DAEP for minor code of conduct violations. The code of conduct was developed by the individual school district.

It began at approximately 11:00 a.m. on Valentine's Day in 2008. Dr. Lemont was on her way to Columbia University in New York City, and her flight was scheduled to depart at 1:15 p.m. 
As she was placing the last of her luggage in her car, the doorbell rang. Imagine her shock to see Donita, her fifteen-year-old grandniece, standing in the doorway without a coat in 20degree weather and with a police officer standing by her side.

Dr. Lemont had received legal custody of her grandniece when Donita's biological mother, addicted to drugs, had abandoned her at four months of age. Donita, who was now in the $10^{\text {th }}$ grade, attended a middle-class, predominantly White school with approximately 95\% White administrators and teachers. In the $2^{\text {nd }}$ grade, Donita had been identified as having special needs, but in the $6^{\text {th }}$ grade she was dismissed from Special Education courses when she scored one point above the cut-off score necessary for special education placement.

According to the police officer, Donita had been suspended from school for three days, sentenced to 21 days in an alternative disciplinary program, and was charged with criminal misconduct that included a $\$ 500$ dollar fine. According to the principal, Donita had staged a nonviolent sit-in with five other students in front of the principal's office. This was in protest to the school administrators' refusal to allow Donita's friend, a young White senior (a closeted intersexed individual who refused to disclose a sex identity) to wear make-up during school hours. Donita felt that it was discriminatory that only girls could wear make-up. The principal told Dr. Lemont that, despite several requests from administrators asking Donita to get up off the floor and go to class, she had refused. As a result, they felt they had no other recourse than the action taken.

Dr. Lemont was horrified by the harshness of the punishment and made an appointment to speak with someone in the school's central administration. A dean of a college of education went with Dr. Lemont to advocate on behalf of Donita. Dr. Lemont pleaded passionately for Donita. She argued that her grandniece had not missed a day of class since preschool, including summer school, because she could so easily fall behind academically. To their chagrin, the appeal was denied. It took threatening a lawsuit and summoning an associate superintendent to get the suspension, sentencing, and charges overturned.

\section{Reflection}

Prior to the meeting, Dr. Lemont did some research on the DAEP program and found that consisted mainly of African American and Hispanic students from low socioeconomic backgrounds, and that those students were not there for serious violations nor received the rehabilitative services that the policy promised, such as counseling, small-classroom instruction, and veteran teachers. For the most part, this school program, like many alternative educational programs, was being used as a dumping ground for "undesirable" students who, once there, received little or no support. Deterioration of these students' academic performance skills and behaviors emerged over time.

The essential question for Dr. Lemont was: If a relative with a Ph.D. along with a dean of a college of education nearly lost a fight in advocating for a student, then how many parents of children in similar DAEPs situations felt powerless in fighting for their child's rights? She imagined that most parents were too intimidated to even try. From a social justice perspective, and regardless of the outcome, Dr. Lemont knew that she had to fight not only for her grandniece, but also for other children in DAEPs. 
In this scenario, all three levels of advocacy were present: client/student, school/community, and public arena. The first level was a relative's passionate desire to empower and advocate on behalf of a student. The second level - school and community collaboration and systems advocacy - was constituted by partnerships among a college of education, school district, parents, and communities of color. At the third level-public arena- as well as social and political advocacy, happened during a town hall meeting that resulted in the attendance of politicians who created and were ultimately responsible for DAEPs in their state.

There were several pathways that Dr. Lemont could have taken throughout the process. Those included a legal battle with the school, taking her grandniece out of the school, or organizing community groups to attack the school district's policies. Instead, she chose the high road. As a result, this incident became the beginning of an ongoing partnership among the college of education, communities of color, parents, community groups, and school districts to reform mandated disciplinary education programs in order to increase access to equal opportunities for children of color. That is, she chose a social justice approach that would not only right a wrong, but would bring people on both sides of the fence together to pool their resources, roll up their sleeves, and become passionately involved in creating a solution together. After all, the African proverb rings true, "It takes a village to raise a child."

Since Donita's incident, members involved convened a town hall meeting and two summits to address education reform: the African American Summit on Education and the Latino Education Summit. Progress has been made toward this partnership, yet it will take more time and more gatherings in order to declare the partnership a success. Additionally, with the help of the village, Donita passed all of her state exams, graduated from high school in May of 2010, and completed her first semester at a local community college.

\section{Case \# 2: Multiheritage Youth in the Schools - Malott}

The 2001 U.S. Bureau of Census cited that, of the total 281.4 million people in the United States, 6.8 million (approximately $2.4 \%$ of the population) indicated that their ethnic background consisted of more than just one race (U.S. Bureau of Census, 2001). In turn, an ever-increasing rate of interracial marriages makes this population one of the fastest growing groups in the U.S. public school system (Lee \& Edmonston, 2005). In this article, we use the terminology multiheritage $(\mathrm{MH})$, in lieu of multiracial, to describe persons of more than one ethnicity/culture or race.

In spite of their large number, $\mathrm{MH}$ persons continue to struggle for recognition of their unique heritage - a struggle whose roots lie in the historical legal and social systems of Colonial America. This history begins with the "one drop" law that legally classified persons with any amount of African American in them as fully African American and the antimiscegenation laws of the $17^{\text {th }}$ and $18^{\text {th }}$ centuries, prohibiting marriages across racial groups (Korgen, 1998). Discrimination was also found in social scientists' claims of genetic and moral inferiority of those from mixed unions (Caste, 1926; Davenport, 1917; Krause, 1941).

Those historical injustices have led to contemporary prejudices against persons of multiple heritages with perceptions that such persons must be "confused" regarding their identity; should choose only "one" racial or ethnic group to whom they are loyal; and that they must be less emotionally "stable" than those of a single heritage (Shih \& Sanchez, 2005). Such beliefs 
are still reflected in a Louisiana judge's recent refusal to marry a Black and White couple (Huffinton Post, 2009), reminding us that such erroneous views continue to profoundly and negatively affect $\mathrm{MH}$ persons.

In the school setting, where modern-day segregation can be observed simply by peering into a school cafeteria, one can imagine the struggle that youth will find in embracing and expressing all aspects of themselves. Not only students, but teachers, counselors, and even school paperwork, often reinforce the social norm that people must identify with only one heritage. Contrary to past concerns regarding the emotional stability of $\mathrm{MH}$ persons, researchers have demonstrated that persons of multiple heritages are as emotionally stable, successful, and possess equal levels of self-esteem as single-heritage persons. However, what researchers have also found, regarding healthy, thriving youth, is that those who are able to fully identify with all aspects of their identity tend to be the healthiest and most well-adjusted (Bracey, Bámaca, \& Umaña-Taylor, 2004; Shih, Bonam, Sanchez, \& Peck, 2007; Shih \& Sanchez, 2005).

\section{Narrative: Maya, the "non-Latina"}

Maya, age 13, was a 3rd generation Mexican American. With Mexican-born grandparents who did not speak English, she could be identified as $\mathrm{MH}$ due to her blend of Mexican and American values, lifestyle, and Spanglish (her own unique mix of Spanish and English language). Maya experienced multiple conflicts with other Mexican-born females and with White children. She was highly sensitive about her own lack of Spanish fluency, as well as a lack of knowledge regarding her Mexican heritage. It seemed that Maya felt marginalized, or outside of two cultures, and she was picked on for belonging fully to neither. She had also internalized prejudices against her own Mexican heritage, which resulted in an internalized negativity regarding her own identity.

As her counselor, I began exploring with Maya the meaning of her Mexican heritage, along with any feelings she related to the disconnection from her culture. However, because I could not act as a cultural role model I recruited Mexican-American community counselors to provide groups addressing this cultural identity. I assessed the resources in the library and worked in conjunction with the librarian to order literature that was more relevant to Latino youth and their identities/histories. I convinced a local Mexican dance instructor to offer after-school classes in the cafeteria once a week and also recruited a wide range of participants for the activities, so that students with generational differences could connect and serve as peer role models for one another.

\section{Reflection}

Social justice advocacy work for MH persons can occur in many forms. As guided by the ACA Advocacy Competencies (Lewis et al., 2003), I largely addressed the client/student and school/community advocacy competencies. Within these categories, I combined acting with (e.g., empowering) the client with actions on behalf of (e.g., advocacy) the client, in an attempt to meet her needs. For instance, selected interventions sought to empower Maya through identifying her cultural strengths and resources and the use of reflection and exploration to increase her understanding of her life and self-identity within the cultural context. I acted as an advocate in creating environmental interventions in collaboration with community organizations (e.g., dance instructor and Latino mental health workers), to provide relevant services and 
resources for the client. I sought broader, systemic change through collaboration with the librarian in adding certain resources, as well as engaging multiple youth in the group and dance intervention.

In addition to these actions, social justice advocacy could have taken additional forms, largely related to client/student and school/community advocacy. These include educating teachers regarding harmful attitudes, beliefs, or actions they should avoid, along with ways to address or reduce harmful behaviors among students; advocating for the rights of both parents to be heard and included in all decisions, especially when one voice is excluded or discounted, if adults perceive one child's race more important or prominent than the other; promoting knowledge of $\mathrm{MH}$ youth in the school setting through educational programs and through educating students, faculty, administration, and staff (Nishimura \& Bol, 1997); advocating for the representation of $\mathrm{MH}$ persons on school paperwork and policies; and sponsoring an advocacy group for $\mathrm{MH}$ youth to work toward local and broader systemic changes.

Maya took to the activities, and she began to connect across cultures. In turn, she began to identify with lost parts of her heritage (as did many other students). Pride replaced internalized racism. Maya's conflicts with peers began to diminish and she found a group of friends to sit with in the cafeteria. In furthering her identity development, she eventually signed up for a Spanish language class and began to connect with her grandparents for the first time.

\section{Case \# 3: Social Justice and Leadership in Service Learning Programming - Flaherty}

Service learning is an experiential educational method that guides students through structured activities design to make a change or contribution to their school and surrounding community. At the heart of service learning is education on the needs and treatment of others and the design and implementation of programming that promotes social justice values (Kurth, 1995). Prejudice and unfair practices regarding gender, class, and disability are some of the concerns that can be affected through service learning projects. Projects that prove to be most effective are those generated by community or school need, recent local or world events, personal experiences with unfair practices, and, most importantly, from the students' interests. In sum, service learning programming is best approached from a collaborative, three-pronged consideration of school and community needs and students' interests (Buchen \& Fertman, 1994).

Implementing a service learning program in the school setting requires a shared vision for intervention, change, and sustained leadership skills. Leadership development, a foundational piece of the program discussed below, is both a cause and a result of a successful servicelearning program. Training students in basic leadership skills enables them to better embrace and promote other-centered projects. Conversely, leadership development training can contribute significantly to students' personal growth and awareness (Beane, 1993).

Service learning experiences can be particularly effective at the middle school level as it complements many of the components of middle level curriculum including exploration, personal development, and measured risk taking. Educational goals and interventions focus on moving middle school youths through direct experiences designed to enhance their perspective of other individuals, the community, and the world. Previously seen as consumers of resources, students trained in leadership and service learning become resources, contributors, and helpers 
to the community and can represent a collaborative gain for students and communities (Fertman, White, \& White, 1996).

The use of school-based service learning programs can promote social justice in conjunction with student skills in simple but profound ways. First, training participants in effective communication skills, conflict resolution strategies, and group dynamics can prepare students as future leaders. Second, weekly meetings to discuss and understand concerns and injustices build students' teamwork skills while generating and promoting projects to address injustices. Third, embedding and connecting the program within the school and community assures a steady, reliable, and collaborative programming base of support through which projects are administered. In turn, such service learning programs can be as creative as the members themselves, with use of the local resources at hand.

Following is an example of one such service learning program, The Leadership in Service Learning program (LSLP), which is an extension of the University of Pittsburgh's Maximizing Adolescent Potentials program, the Leadership Development Network. This training initiative has served area youth for over 20 years in a variety of forms. It is noteworthy to mention that the program is a two-time recipient of the American Association of University Women and a Great Ideas grant, as well as a recent recipient of a program grant from the local Parent Teacher organization (PTO).

\section{Narrative}

Through the LSLP program, I train students in effective leadership skills and position them to give and learn through service projects that benefit the school and extended community. I advertise this program to school personnel and community agencies as a resource for developing middle school students' leadership skills through service. Once trained, department heads, principals, teachers and members of the community call on these students to serve as peer leaders, act as mentors, assist with varied projects, problem solve, and address other school and community needs. The students and I use school and community resources to help implement projects that promote social justice in the areas of poverty, gender, disability, and promotion of peace. This collaborative exchange between students, school and community is an exciting and effective method for more comprehensive approaches to addressing issues of unfairness or injustice.

Teachers, counselors and principals recommend middle school students who have demonstrated an interest in helping those in need, or who may benefit from developing personal leadership skills, at the end of their sixth grade year. I intentionally scaffold the selection of student participants in an effort to reach an economically and educationally diverse group of participants. To do this, I ask referring professionals to nominate a group of students from each of the six municipalities that feed into the school. In this way, the socioeconomic, cultural and contextualized issues and concerns for each community serving the school are equally represented. This effort also brings together students with differing community exposures and worldviews, allowing them to learn from one another as well as to work together to address a variety of school, community, and global issues.

I require nominated students to participate in a three-day experiential training that develops individual, shared, and applied leadership skills and concepts. The focus of this training is to 
build effective communication and conflict resolution skills, and to learn how to share leadership in groups. I provide skill instruction in a variety of formats and tailor practice activities around the goals of the instructional experiences. I expect and encourage students throughout the training sessions to examine and bring to light issues of unfairness and injustice that affect marginalized groups.

Upon completion of the training, students develop service projects to address concerns identified in the schools, community, and world at large. They create a specific action plan to address concerns and propose their projects to school administrators. I assume a supportive role through facilitating collaboration between administration, building/district departments, PTOs, and community organizations.

\section{Reflection}

Present in this work are the client/student and school/community levels of advocacy. The client/student level is my role as the program facilitator empowering those students to become advocates with the skills to be able to identify and create developmentally appropriate projects that address those in need. The school/community level of advocacy is promoting school and community collaboration for change. We facilitate and support our alliances with involved stakeholders in order to facilitate change. This is done in two ways: (a) alerting community and school groups about the concerns and (b) being consistent with the Trans-theoretical Model of Change (Prochaska, Norcross \& DiClemente, 1994).

It is my goal to give voice to student issues and concerns, but it is essential to first provide students with the skills, support, and opportunity to effect change. Basic interpersonal skill development and a place to develop those skills comprise the heart of this program. The client/student advocacy continues with the leadership in-service learning. Once trained, I support my students' leadership goals by forging and maintaining the educational and community relationships that hold a stake in the student's success in providing service. My position within the school setting as a long time agency consultant affords me the freedom to create service-learning opportunities wherein my students can grow through giving.

Because personal leadership skills precede necessarily those that are shared or applied, I promote the following individual leadership behaviors and values across the duration of the program by requiring that students: (a) honor their commitment first to family and academics; (b) follow through, or "W = T" (that is, make your walk equal your talk); and (c) speak only what is true, kind, and necessary, dubbed the "TKN rule." These rules provide my students with a framework and expectation to do what they say they will do, and empowerment to voice responsibly their opinions. My students exit the program having witnessed firsthand the importance of advocacy and collaboration as a key to success. They are better trained and positioned to advocate against, and to challenge and change, unjust conditions in their environments.

\section{Discussion}

The above topics were presented by the three authors to an audience of approximately 30 professionals, largely school counselors, at the 2010 MSJLDA. The content and quality of the comments during the presentation showed us that the topics were useful and timely for many 
of the workshop participants. Multiple questions were raised with regard to applying the session content to individual professional settings, and audience members were eager to speak, which resulted in a lack of time for inclusion of all voices. We considered these as positive signs of audience interest and reception, which indicated that the information presented was pertinent and compelling for the group and, hopefully, that it inspired some future form of social justice action.

At the conclusion of the session, we provided participants with numerous suggestions on ways to apply social justice advocacy in school settings. We also offered individual support to participants, should they require further information or consultation for the implementation of suggested interventions or programs. It was encouraging to us that the participants were clearly open, receptive, and interested in using the concepts we presented; indeed, many openly expressed being committed to the promotion of social justice.

Audience members' written feedback indicated that they perceived the presentation as offering "new viewpoints, strategies, and action[s]" regarding social justice leadership in the schools. Participants reported gains the following areas as a result of our presentation: (a) education: increased understanding of social justice challenges relevant to the school setting; (b) personal: interest to continue to "self-educate" and to "examine my own identity biases and perception[s];" and (c) action: as a participant indicated, "we had about 15 strategies/actions in our 'action plan."'

Meaningfully, audience members were concerned with the barriers associated with social justice work in the schools. One member wrote of the shortage of counselors in the school settings and that existing counselors are burdened frequently with non-counselor duties that reduced their ability to engage in social justice advocacy. This begged the questions of how to advocate for our profession, to increase counselor's numbers in the school settings and reduce the inappropriate duties they are often expected to complete.

In addition to these concerns, another audience member inquired as to how one can "manage personal risk in being a social justice advocate in schools." Indeed, we acknowledge that there is always a risk in engaging in social justice advocacy, as social justice efforts are often viewed as outside the 'norm' and as threatening to dismantle what is known and comfortable.

Even those who believe in justice find social justice action to be difficult due to the risks involved with upsetting others, particularly those in power, and the discomfort of making others uncomfortable. For example, for Dr. Lemont and the Dean of the College of Education fighting a school system certainly had major ramifications and risks to maintaining the delicate relationship that existed between the district and the college of education.

We recommend people find a community of support when taking such risks and that this community may be found among persons within their work system. The support system could also include external, social justice-minded persons, such as church members, community advocacy groups (such as antiracism groups), or a carefully selected group of friends. In addition, managing the risks that accompany systemic growth and change requires advocates to focus their collaborative work on a combination of three areas: (a) the core values/mission statement of the system; (b) the professional and ethical guidelines of the advocates; and (c) the developmental needs of the students. If professionals can focus on the overall, larger 
picture of their efforts, they can often see beyond the individual reactions of those around them.

Another answer to managing personal risk with social justice action is to develop strong relationships with those we may be confronting, as opposed to perceiving such relationships as adversarial. As school professionals, we share the same goals for our students - good physical and mental health, high academic achievement, and a successful work/career. Approaching disagreements as an honorable undertaking is not new in schools; in fact, the exchange of differing ideas and effective conflict resolution within the educational setting id not only desirable but is part of the curriculum in any $\mathrm{K}-12$ school setting. Reminding ourselves and others of our common goals, along with the growth to be found in disagreement, can allow us to make a human connection with school colleagues. Ultimately, taking such a stance can better ensure a positive response as we invite them to accompany us, as allies, in making social justice changes.

\section{Suggested Action Strategies}

There are multiple ways to engage in social justice advocacy in school settings-some subtle and others more overt and challenging. There are also multiple levels, from individual to systemic, on which to engage. Advocacy tactics need to suit the counselor's style and skill level while remembering that discomfort may be a necessary consequence of certain endeavors. Actions must be tailored to each particular setting, with involvement of as many supportive persons or organizations as possible.

The following suggestions are based on what we learned during this conference's presentation, follow up feedback, and our reflections based on ACA Social Justice and Advocacy Competencies (Lewis et al., 2003):

- Organize a town hall meeting with parents, schools, community groups, and colleges of education. Within such meetings identify areas of injustice that need to be addressed, along with members from each group willing to take action and effect change.

- Hold all stakeholders accountable for the success of students confined in disciplinary alternative educational programs. This includes applying a systematic procedure for assessing the efficacy of disciplinary programs and those students affected by it.

- Empower students as change agents, in a developmentally appropriate fashion, by inviting direct student participation in program decision-making. For example, strategically soliciting student feedback about academic and nonacademic school events or programs (e.g., speakers, use of extra spaces, community collaborations, etc.) can greatly empower youth in shaping their school experiences.

- Embed a service-learning program through strong partnership among and between administration, teaching staff, community organizations and the PTO. For example, building service projects around the current needs of the school, PTO fundraisers, and community needs can forge a durable and mutually beneficial alliance between service learning programs and schools. 
- Create a culture of acceptance of all youth. In regards to $\mathrm{MH}$ youth, it is important to educate staff, youth, and faculty, while insisting that library materials, school forms, and visuals in halls and offices be inclusive.

- Support policies and promote a culture demonstrating that racism will not be tolerated; recruit youth to educate teachers and administrators regarding racism against their group, which is often overlooked or even enacted by the adults themselves. School counselors can also play a part in identifying and recruiting educators to address such topics during required teacher training in-services.

\section{Conclusion}

It is clear, from audience members' enthusiasm throughout this presentation, that the topic of social justice leadership in the schools is perceived as a viable one for those working in, or with, schools. It is also clear that audience members perceived multiple barriers to achieving such work, including the need to self-educate, to continue to assess one's own personal biases, and to find support in managing any backlash that may result from social justice advocacy work. We believe there should be a greater focus in the literature regarding advocacy specific to the schools, which addresses the above issues, to ensure that all youth across the nation receive quality, and just, educational experiences.

\section{Contact information/Correspondence:}

Aretha Faye Marbley, Ph.D.

Texas Tech University

College of Education, P.O. Box 41071

Lubbock, TX 79409-1071.

E-mail: aretha.marbley@ttu.edu

Krista M. Malott, Ph.D., Department of Education, Villanova University, Villanova, Pennsy/vania; Ann Flaherty, M.Ed., School of Education, University of Pittsburgh, Pittsburgh, PA; Aretha F. Marbley, PhD., and Helyne Frederick, Department of Education, Texas Tech University, Lubbock, TX. 


\section{References}

Advancement Project and The Civil Rights Project at Harvard University. (2000). Opportunities suspended: The devastating consequences of zero tolerance and school discipline policies. Retrieved May 29, 2010 from http://www.law.harvard.edu/groups/civilrights.

American School Counselor Association. (2003). The ASCA National Model: A framework for school counseling programs. Alexandria, VA: Author.

Barbarin, O. A. (2010). Halting African American boys' progression from pre-K to prison: What families, schools, and communities can do! American Journal of Orthopsychiatry, 80, 8188. doi: 10.1111/j.1939-0025.2010.01009.

Beane, J. (1993). A middle school curriculum: From rhetoric to reality (2nd ed.). Columbus, $\mathrm{OH}$ : National Middle School Association.

Bracey, J. R., Bámaca, M. Y., \& Umaña-Taylor, A. J. (2004). Examining ethnic identity and selfesteem among biracial and monoracial adolescents. Journal of Youth \& Adolescence, 33, 123-132. doi: 0047-2891/04/0400-0123/0.

Buchen, I., \& Fertman, C. (1994). Creating a culture of service: Effective service- learning. Warminster, PA: Marco Products.

Caste, W. E. (1926). Biological and social consequences of race crossing. American Journal of Anthropology, 9, 145-156. doi: 10.1002/ajpa.1330090212.

Cortez, A., \& Robledo-Montecel, M. (1999). Disciplinary alternative education in Texas what is needed: What is known. Intercultural Development Research Association. Retrieved on April, 3, 2010 at www.idra.org.

Davenport, C. B. (1917). The effects of race intermingling. Proceedings of the American Philosophical Society, 56, 364-368.

Fertman, C., White, G. P., \& White, L. J. (1996). Service learning in the middle school: Building a culture of service. Columbus, $\mathrm{OH}$ : National Middle School Association.

Hipolito-Delgado, C. P., \& Lee, C.C. (2007). Empowerment theory for the professional school counselor: A manifesto for what really matters. Professional School Counseling, 10, 327 - 332.

Hudson, S. (2007). Executive Director Newsletter. White Bear Center for the Arts. Retrieved from http://whitebeararts.org/?300604/Exec\%20Dir\%20Letter/NewsletterSummber2007.pdf.

Huffington Post. (2009, October 15). Interracial couple denied marriage license by Louisiana justice of the peace [Web blog post]. Retrieved from http://www.huffingtonpost.com.

Korgen, C. O. (1998). From Black to biracial. Westport, CT: Praeger Publishers. 
Krause, W. W. (1941). Race crossing in Hawaii. Journal of Heredity, 32, 371-378.

Kurth, B. (September, 1995). Learning through using service learning as the foundation for a middle school advisory program. Middle School Journal, 271), 35-41.

Lee, S. M., \& Edmonston, B. (2005). New marriages, new families: U.S. racial and Hispanic intermarriage (Report No. 60). Washington, DC: Population Reference Bureau.

Lewis, J., Arnold, M. S., House, R., \& Toporek, R. (2003). ACA Advocacy competencies [Electronic version]. Retrieved from http://www.counseling.org/Publications.

Nishimura, N., \& Bol, L. (1997). School counselors' perception of the counseling needs of biracial children in an urban educational setting. Research in the Schools, 4, 17-23.

Prochaska, J. O., Norcross, J. C., \& DiClemente. C. C. (1994). Changing for good: The revolutionary program that explains the six stages of change and teaches you how to free yourself from bad habits. New York: Morrow.

Ratts, M., DeKruyf, L., \& Chen-Hayes, S. F. (2007). The ACA advocacy competencies: A social justice advocacy framework for professional school counselors. Professional School Counseling, 11, 90-97.

Shih, M., Bonam, C., Sanchez, D. T., \& Peck, C. (2007). The social construction of race: Biracial identity and vulnerability to stereotypes. Cultural Diversity and Ethnic Minority Psychology, 13, 125-133. doi: 10.1037/1099-9809.13.2.125.

Shih, M., \& Sanchez, D. T. (2005). Perspectives and research on the positive and negative implications of having multiple racial identities. Psychological Bulletin, 131, 569-591.

Steele, J. M. (2008). Preparing counselors to advocate for social justice: A liberation model. Counselor Education and Supervision, 48(2), 74-85.

Tatum, B. D. (2003). "Why are all the Black kids sitting together in the cafeteria?": A psychologist explains the development of racial identity. New York: Basic Books.

Texas Education Agency. (2007). Disciplinary alternative education program practices. Policy Research Report No.17 (Document, No. GE07). Austin, TX: Author. Retrieved from www.tea.state.tx.us/research.

U.S. Bureau of Census. (2001). Mapping census 2000: The geography of U.S. diversity. Washington, DC: U.S. Government Printing Office. 